\title{
FUNÇÃO SOCIAL DO TRIBUTO, LIVRE INICIATIVA E LIVRE CONCORRÊNCIA SOB A ÓTICA DA PROTEÇÃO DOS DIREITOS FUNDAMENTAIS
}

\author{
Aldo Aranha de Castro ${ }^{1}$ \\ Vanessa Cristina Lourenço Casotti Ferreira da Palma ${ }^{2}$
}

Resumo: O objetivo do presente trabalho é fazer uma análise sobre a livre concorrência e a livre iniciativa sob o viés tributário, com o objetivo de garantia e preservação dos direitos fundamentais. Deste modo, será destacada a importância dos direitos fundamentais e da função social do tributo como instrumento para a realização de políticas públicas. Após, será abordado especificamente acerca da livre iniciativa e da livre concorrência com o intuito de garantia e proteção dos direitos fundamentais. $\mathrm{O}$ trabalho se desenvolverá através do método dedutivo, por meio de pesquisa bibliográfica, para confirmar a análise realizada.

Palavras-chave: Direitos Fundamentais; Direitos Humanos; Função Social do Tributo; Livre Concorrência; Livre Iniciativa.

\section{TAX SOCIAL FUNCTION, FREE ENTERPRISE AND FREE COMPETITION UNDER THE PROTECTION OF THE FUNDAMENTAL RIGHTS}

\begin{abstract}
The purpose of this paper is to analyze free competition and free enterprise under a tax bias, with the objective of guarantee and preservation of the fundamental rights. In this way, it will be highlighted about the importance of the fundamental rights and of the tax social function as an instrument for the realization of public policies. Afterwards, it will be specifically addressed about free enterprise and free competition in order to guarantee and protect fundamental rights. The work will be developed through the deductive method, through bibliographic research, to confirm the analysis performed.
\end{abstract}

Keywords: Fundamental Rights; Human Rights; Tax Social Function; Free Competition; Free Enterprise.

\section{Introdução}

\footnotetext{
${ }^{1}$ Doutorando em Direito - Universidade de São Paulo - USP (DINTER USP-UFMS). Mestre em Direito pela da Universidade de Marília - UNIMAR. Especialista em Direito Civil e Processo Civil pela Universidade Estadual de Londrina - UEL. Graduado em Direito pela Universidade de Marília (UNIMAR). Professor Assistente da Universidade Federal de Mato Grosso do Sul - UFMS, Campus de Três Lagoas. Mediador e Conciliador Judicial cadastrado no Tribunal de Justiça do Estado de Mato Grosso do Sul. Bolsista CAPES (O presente trabalho foi realizado com apoio da Coordenação de Pessoal de Nível Superior - Brasil (CAPES) - Código de Financiamento 001). E-mail: aldodecastroadv@hotmail.com ; aldo.aranha@usp.br

2 Doutora em Educação pela UFGD. Mestre em Direito - UNIVEM. Docente Efetiva do Curso de Direito da UFMS, campus de Três Lagoas/MS. vanessacasotti@hotmail.com
} 
A área jurídica é muito interessante, pois possibilita um leque de oportunidades, diversas ideias a se desenvolver, sob as mais variadas vertentes. Um dos temas que ganha bastante destaque, até mesmo em razão de se manter sempre atual, é o relativo aos direitos e garantias fundamentais, que estão previstos expressamente na Constituição Federal e são defendidos quase que de forma uníssona, tanto pelos juristas quanto pela sociedade como um todo.

E é nessa necessidade de preservação dos direitos e garantias fundamentais que, num primeiro momento, pauta-se o presente trabalho, que tem por objetivo fazer uma análise acerca da importância dos direitos fundamentais sob um viés tributário e econômico.

Para tanto, em uma primeira etapa, cumpre situar os direitos fundamentais na Constituição Federal, destacando a importância de sua proteção para a garantia dos direitos da sociedade. Nesse momento, cumpre fazer uma abordagem acerca da função social do tributo e apresentar como se dá a implementação das políticas públicas para a garantia do desenvolvimento econômico e social e, em especial, para que haja a redução das desigualdades sociais e regionais.

Uma vez tecidos tais comentários, que expõem uma estrutura mais social do direito tributário, com vistas à proteção do indivíduo (não apenas como contribuinte, mas principalmente como cidadão de um Estado Democrático de Direito), é possível desenvolver um estudo acerca da aplicabilidade dos princípios da livre iniciativa e da livre concorrência para a garantia do desenvolvimento econômico e social, a fim de que o mercado tenha um equilíbrio e, deste modo, seja possível a proteção da sociedade.

O trabalho em questão se justifica ante ser possível se deparar com a grande desigualdade socioeconômica em que a população brasileira está alojada, o que traz um grande distanciamento entre uns (poucos) que possuem uma renda exorbitante e outros (muitos) que vivem, ou muitas das vezes apenas sobrevivem, com um valor irrisório, muitas vezes beirando, por si só, neste fato, à existência de uma vida sem a proteção e garantia à dignidade humana.

O trabalho será desenvolvido através do método dedutivo, e com a utilização de pesquisa bibliográfica (estruturada em doutrinas e em artigos científicos sobre o tema), onde se pretende trazer uma análise e reflexão sobre o tema com o objetivo de se trazer um equilíbrio de mercado e, por conseguinte, social. 


\section{A importância dos direitos fundamentais e a presença da função social do tributo para nortear as políticas públicas}

Os direitos fundamentais são inerentes a cada indivíduo, que merecem sua ampla e integral preservação. Todavia, para que a proteção de tais direitos ocorra de modo satisfatório, é necessário o emprego de diversos mecanismos, nas mais diversas áreas jurídicas.

É possível observar a proteção aos direitos fundamentais quando se trata da garantia do acesso à justiça, previsto no artigo $5^{\circ}$, inciso XXXV da Constituição Federal, e também quando se busca a preservação da dignidade da pessoa humana, que é, inclusive, fundamento da República Federativa do Brasil (art. $1^{\circ}$, inc. III, CF/88).

Também é possível pensar em preservação dos direitos fundamentais quando se aborda o direito tributário, uma vez que esse ramo do direito, que se ocupa, em sentido geral, no sentido de arrecadação de tributo, mas não tem apenas esse intuito, pois é nítida a presença de uma função social do tributo, bem como de políticas públicas (fiscais e extrafiscais) que protegem o cidadão, por exemplo, da existência de um tributo com efeito de confisco.

Nesse viés tributário e econômico (com destaque à livre iniciativa e à livre concorrência), é que se pretende abordar os direitos fundamentais no decorrer do trabalho.

Antes disso, cumpre salientar que os direitos e garantias fundamentais estão previstos explicitamente na Constituição Federal, notadamente em seus artigos $5^{\circ}$ a 17 (embora não se restrinjam a apenas esses dispositivos), que tratam do título específico "Dos Direitos e Garantias Fundamentais".

Nessa parte do diploma constitucional encontram-se importantes garantias para a proteção da sociedade, uma vez que, no capítulo primeiro, trata acerca dos direitos e deveres individuais e coletivos. Essas garantias são intimamente ligadas à pessoa, e aqui se pode observar a necessidade de proteção à vida, liberdade, igualdade, segurança e propriedade, que garantirão a dignidade ao indivíduo, nos termos ali presentes.

O segundo capítulo aborda os direitos sociais, que objetivam garantir a independência e a vida digna aos indivíduos, tanto que os direitos ali presentes se referem à educação, saúde, alimentação, trabalho, lazer, proteção à maternidade e à infância e assistência aos desamparados, entre outros. Nesse caso, objetiva-se a redução das desigualdades sociais para uma melhor qualidade de vida a todos. Nesse item, diversas são as possibilidades de incentivo que podem ser dadas, em todas as áreas (como, por exemplo, o 
Programa Universidade para Todos - PROUNI -, na área da educação, ou o incentivo à contratação de pessoas idosas ou com deficiência, para a inclusão no mercado de trabalho). Deste modo, o direito tributário pode atuar positivamente, com a implementação de políticas públicas, como é observado no caso da Zona Franca de Manaus, que visa reduzir as desigualdades sociais e regionais, nos termos do artigo 170, inciso VII, da CF/88, ou mesmo através das chamadas "construções verdes", em que se incentiva a preservação de áreas verdes nos centros urbanos (com, por exemplo, a redução de IPTU em determinada localidade que mantenha parte de sua residência com árvores).

O capítulo III deste título da Carta Constitucional trata da Nacionalidade, ou seja, visa garantir a proteção (mas também estabelecer os deveres) dos brasileiros natos e naturalizados (especificando cada um deles).

Por fim, os capítulos IV e V tratam, respectivamente, dos direitos políticos e dos partidos políticos. Os direitos políticos se constituem na forma de a pessoa poder exercer sua cidadania, não apenas no sentido de poder votar, como também de ser votado. Já quanto aos partidos políticos, regulam a criação, e existência em geral, dos partidos políticos. Esse tema, por si só, esgotaria mais de um trabalho específico, não sendo o foco do presente trabalho.

Assim sendo, é importante que todos estejam cientes da existência de direitos fundamentais que devem ser protegidos, com o objetivo de se preservar os direitos humanos em sua integralidade. Em linhas gerais, os direitos humanos, pela conceituação clássica, são os relativos à liberdade (primeira geração), igualdade (segunda geração) e solidariedade/fraternidade (terceira geração), sendo que eles estão protegidos pela esfera constitucional, conforme supramencionado.

Ademais, relacionando os temas até agora abordados, merece destaque que a dignidade da pessoa humana deve ser amplamente protegida, não só sob os parâmetros legais, como também através de parâmetros constitucionais, em respeito aos diversos tratados internacionais que guardam relação com o tema (notadamente a Declaração Universal de Direitos Humanos, mas também os diversos documentos que visam à proteção do indivíduo).

Para que a dignidade humana realmente tenha garantido o seu valor e seja efetivamente respeitada, diversos são os mecanismos a fim de viabilizar que o indivíduo possa viver em harmonia. Neste momento, entra em cena o direito tributário, que é uma área do direito (dentre tantas outras) que se preocupa com a dignidade da pessoa humana por meio de uma função social do tributo (isso significa que o direito tributário não possui unicamente o 
intuito arrecadatório). Tal função permite a criação de políticas públicas (fiscais e extrafiscais) que viabilizem a busca pela redução das desigualdades sociais e regionais, objetivando um equilíbrio entre as pessoas, para que haja, de fato, uma vida digna.

É importante a análise da função social do tributo, uma vez que, quando se fala nela, “[...] tem-se em vista seu caráter social, o respeito à dignidade da pessoa enquanto ser humano e a busca pela redução das desigualdades regionais e sociais existentes [...]” (RIBEIRO; CASTRO, 2013, p. 2). Deste modo, pode-se visualizar um caráter mais social de um instituto que, em sua maioria, só é visto como fator de oneração da população.

Ademais, a conceituação de função social do tributo é feita por Maria de Fátima Ribeiro e Aldo Aranha de Castro (2013, p. 3) da seguinte forma:

Por função social do tributo entende-se que é a forma como o Estado pode propiciar à sociedade a redução das desigualdades sociais e regionais, proporcionando meios adequados para desenvolvimento de certas regiões que se encontram em contraste com os grandes centros econômicos do país, através de incentivos fiscais que possibilitem uma equiparação entre estes e aquelas, com a possibilidade de um aumento no número de empregos, com um equilíbrio social maior entre as regiões menos desenvolvidas e as mais desenvolvidas fazendo, assim, com que haja efetivamente o desenvolvimento nacional.

Com isso, é possível dirimir quaisquer dúvidas acerca da presença do direito tributário também no aspecto social, inclusive através de premissas constitucionais (como os princípios tributários e da ordem econômica, além dos já conhecidos fundamentais). Isso porque, princípios como o da vedação do confisco, da capacidade contributiva, da legalidade e da isonomia tributária, são essenciais para não se atribuir uma oneração excessiva a quem pode não ter condições de arcar com tais ônus.

Além desses, há os princípios previstos no artigo 170 da Constituição Federal, que tratam da ordem econômica e financeira, em especial o já mencionado anteriormente, previsto no inciso VII de referido diploma, que objetiva a redução das desigualdades regionais e sociais. Esses são aspectos claros da participação tributária nas questões sociais, visando proporcionar um equilíbrio para a sociedade, por este motivo, a tributação social é “[...] aquela que respeita o que é inerente à sociedade no contexto social dos ditames constitucionais" (RIBEIRO, 2008, p. 179).

Com essa compreensão, tanto da função social do tributo, quanto da tributação social a ela inerente, vale a pena exemplificar, em linhas gerais, alguns dos casos práticos em que se 
dá a implementação das políticas públicas. Primeiramente, cumpre apresentar o conceito de política pública, como sendo:

[...] o conjunto de um planejamento tributário efetivo e bem desenvolvido, de programas elaborados pelo governo que, prevendo o custo orçamentário e o impacto sobre o orçamento, concedem incentivos fiscais com o intuito de desenvolvimento econômico, cuja efetividade se dará através de ações, isto é, da colocação em prática dessas medidas de benefício à população (RIBEIRO; CASTRO, 2013, p. 06).

Sobre a questão do desenvolvimento econômico, vale destacar que essa expressão “[...] deve ser utilizada no sentido de representar um estado de harmonia entre o crescimento e a modernização da economia com a proteção dos valores sociais" (ELALI, 2007, p. 45).

Desta feita, diversos são os exemplos que podem ser apresentados, no tocante às políticas públicas, tais como os incentivos ambientais em áreas urbanas, os incentivos concedidos à Zona Franca de Manaus e aqueles relativos ao Programa Universidade para Todos (PROUNI), entre outros.

Em relação aos incentivos ambientais, ou incentivos "verdes", forma comumente denominada, referem-se à concessão de incentivos, por parte de diversos municípios, no sentido de reduzir determinados tributos, para que a pessoa mantenha uma área verde em sua propriedade, com a finalidade de conservação ambiental e, por conseguinte, manutenção do ecossistema para, assim, preservar o meio ambiente de forma ecologicamente equilibrada, conforme o artigo 225 da Constituição Federal.

O Programa Universidade para Todos (PROUNI), por sua vez, “[...] visa promover o acesso da população de baixa renda ao ensino superior" (RIBEIRO; CASTRO, 2013, p. 08). Em razão desse programa, são concedidos incentivos (como a redução e/ou isenção de alguns impostos e contribuições) às instituições privadas, quer elas tenham, ou não, fins lucrativos, para que disponibilizem vagas para ingresso no ensino superior àquelas pessoas que se enquadrem nos requisitos do programa.

Por fim, quanto à Zona Franca de Manaus, este é um importante exemplo da busca pelo equilíbrio e redução das desigualdades regionais e sociais, pois se trata de incentivos concedidos desde o ano de 1967 (e que já está prorrogado até o ano de 2073, em razão da Emenda Constitucional n. ${ }^{\circ}$ 83, de 2014) para a região amazônica (em específico às definidas pela Superintendência da Zona Franca de Manaus - SUFRAMA). Nessa região, são 
concedidos "[...] incentivos fiscais e extrafiscais para aqueles que decidirem instalar seus empreendimentos industriais naquela região" (RIBEIRO; CASTRO, 2013, p. 11). São reduções ou isenções sobre, por exemplo, o imposto de importação, isenção quanto ao imposto sobre produto industrializado, bem como outros incentivos, na área do imposto de exportação, do imposto sobre a renda, do programa de integração social (PIS) e do financiamento da seguridade social (COFINS).

Esses benefícios são muito vantajosos, mas merecem uma contraprestação, e a fiscalização por parte do governo e da sociedade, para que realmente se reverta para a redução das desigualdades sociais que existem naquela região em comparação com o Centro-Sul do Brasil. Se for fortalecida a região e referida Zona Franca, será um avanço muito grande para a região Norte do Brasil, que possui uma vasta riqueza natural.

Uma vez apresentados esses exemplos, e compreendida a noção de função social do tributo, bem como a relevância da preservação dos direitos fundamentais, cumpre salientar que, para o desenvolvimento nacional, não apenas o econômico, mas também o social, é necessário que todos se engajem e participem, inclusive as empresas, que podem contribuir (e muito) para uma sociedade mais harmônica e fraterna.

Através da livre iniciativa e da livre concorrência é possível contribuir para o equilíbrio social pois, por meio da estruturação do mercado a sociedade pode se beneficiar, desde que haja lisura nesses procedimentos, evitando-se formação de cartéis e outras atitudes que tragam prejuízo à sociedade e que desvirtua esses preceitos previstos constitucionalmente e que visam garantir a dignidade humana.

\section{A aplicabilidade dos princípios da livre iniciativa e da livre concorrência com vistas ao desenvolvimento econômico e social}

A livre iniciativa está relacionada com o livre exercício da atividade econômica, ao passo que a livre concorrência se baseia nos princípios da isonomia e legalidade tributária, bem como no da uniformidade geográfica, sendo dever do poder público garantir a liberdade de concorrência, com vistas a atender à sociedade, para que esta não se sinta lesada e sem opção de escolhas. 
É necessário entender que os direitos fundamentais são essenciais e precisam ser protegidos e garantidos, e um dos modos em que tais garantias podem se dar é através da livre concorrência e da livre iniciativa.

De modo bem simples, o modelo ideal de concorrência seria aquele onde existem muitos vendedores ofertando determinado produto, e muitos compradores, e não aquele em que haveria um indivíduo, isolado, que pudesse controlar totalmente o mercado. Todavia, este modelo não consegue ser tido como absoluto, vez que há casos de monopólios e oligopólios que restringem essa liberdade, diminuindo a concorrência, ou até mesmo anulando-a.

Antes de conceituar propriamente dito a livre concorrência, faz-se por bem abordar, em linhas gerais, os três princípios tributários sob os quais se pauta a livre concorrência.

O primeiro deles é o da legalidade tributária (ou estrita legalidade, ou reserva legal). Ele é considerado o princípio mais importante relacionado à esfera tributária, e tem sua previsão no artigo 150, inciso I, da Constituição Federal, que diz "ser vedado à União, aos Estados, ao Distrito Federal e aos Municípios exigir ou aumentar tributo sem lei que o estabeleça". Esse princípio limita a atuação do ente tributante, não permitindo que se cobre ou aumente o tributo sem que a lei assim estabeleça.

Para Sacha Calmon Navarro Côelho (2010, p. 173), “[...] o princípio da legalidade significa que a tributação deve ser decidida não pelo chefe de governo, mas pelos representantes do povo, livremente eleitos para fazer leis claras". Deste modo, a legalidade tributária impõe um limite ao poder de tributar, pois não é possível a criação ou majoração de tributos, senão em virtude de lei (nullum tributum sine lege). Já o prazo para pagar o tributo não é ato essencial, podendo ser feito por Decreto.

Há, contudo, exceções ao princípio da legalidade aqui tratada, onde o Poder Executivo estabeleceu a alíquota de quatro impostos: II, IE, IPI e IOF. Estes, segundo Sacha Calmon Navarro Côelho (2010, p. 182), “podem ter suas alíquotas alteradas e, pois, aumentadas (quando se restabelece a redução inicial) sem prévia lei, por simples ato administrativo, atendidas as condições e os limites a serem fixados em lei autorizativa". Esta exceção está prevista no Art. $153, \S 1^{\circ}$, da CF/88.

O princípio da isonomia tributária, ou igualdade tributária, por sua vez, está previsto no artigo 150, inciso II, da CF/88, e diz que as pessoas políticas mencionadas no caput estão vedadas de "instituir tratamento desigual entre contribuintes que se encontrem em situação 
equivalente, proibida qualquer distinção em razão de ocupação profissional ou função por eles exercida, independentemente da denominação jurídica dos rendimentos, títulos ou direitos".

As pessoas políticas não podem estabelecer tratamento diferenciado, se estiverem equivalentes. Visa acabar com determinados privilégios que existiam antes da $\mathrm{CF} / 88$, o que acaba por limitar o poder de tributar, de modo a dar tratamento igual aos contribuintes. Humberto Ávila (2010, p. 369) aborda este princípio ao dizer que:

O princípio da igualdade abrange o dever de tratar os iguais da mesma forma e a proibição de desigualar arbitrariamente os contribuintes. $\mathrm{Na}$ concretização desta exigência, deve-se investigar se a distinção legal era permitida e se a lei tratou desigualmente em hipótese na qual isso era obrigatório. Desigualdade arbitrária, isto é, sem justificação constitucional, é inconstitucional. (ÁVILA, 2010, p. 369).

Pode-se citar como exemplo de igualdade tributária, a questão do Imposto sobre a Renda. Neste, determinado contribuinte, se auferir uma renda menor, pagará menos ou nenhum imposto, ao passo que aquele que obtiver uma renda maior, e efetivar isso em sua declaração, pagará um montante maior a título desse mesmo imposto, ou seja, haverá um imposto progressivo, quanto maior a renda, maior o valor a ser pago.

O terceiro princípio no qual se pauta a livre concorrência é o da uniformidade geográfica, prevista no artigo 151, inciso I, da CF/88, e ele proíbe a União de estabelecer tributos que não sejam uniformes em todo o território nacional, nem permitir diferenciação tributária para um Estado em detrimento de outro.

Luciano Amaro (2009, p. 137) pontua este princípio da seguinte forma:

[...], a Constituição estabelece a uniformidade dos tributos federais em todo o território nacional, e veda distinção ou preferência em relação a Estado, ao Distrito Federal ou a Município, em detrimento de outro (art. 151, I). Há ressalva expressa para os incentivos regionais, destinados a promover 0 equilíbrio do desenvolvimento socioeconômico entre as diversas regiões do País, com fundamento em que situações desuniformes não podem ser tratadas de modo uniforme.

O que se observa é que existe, todavia, a título de exceção, a possibilidade de a União conceder incentivos fiscais para promover o equilíbrio entre as regiões. Nesse caso, será possível que os tributos federais tenham alíquotas diferenciadas. Um exemplo é o já 
mencionado anteriormente, quanto aos incentivos da Zona Franca de Manaus, que visa promover certo equilíbrio entre aquela região e as demais.

Uma vez tratados desses três princípios tributários sob os quais se pauta a livre concorrência, pode-se conceituá-la como sendo "[...] liberdade de concorrência, desdobrada em liberdades privadas e liberdade pública" (GRAU, 2010, p. 212).

A livre concorrência é baseada na competitividade que, infelizmente, em alguns casos não ocorre. E, para isso, faz-se importante o papel do Estado como interventor da Economia, com vistas a assegurar os princípios não só constitucionais fundamentais como os da ordem econômica e os tributários. Com isso, o Estado, através de meios antitrustes, intervém na economia para que uma empresa que, porventura, detenha domínio econômico sobre determinado produto, não venha a cometer abusos em virtude deste monopólio que detém.

A repressão a esse abuso de poder econômico, que tenha por objetivo eliminar a concorrência, o aumento arbitrário (e sem limites) dos lucros e o domínio do mercado, deve ser feita por lei, conforme preconiza o Art. $173, \S 4^{\circ}$, da CF/88. Deste modo, compete ao Estado a tarefa de regular o mercado, e proteger o consumidor e a sociedade em geral.

Este princípio, bem como os demais da ordem econômica, é pautado pela finalidade de justiça e dignidade humana (tanto no contexto coletivo quanto de indivíduo particularizado) sendo, para tanto, responsabilidade do Estado a proteção da sociedade, a fim de coibir e corrigir os abusos porventura existentes, para que se preserve a livre concorrência e, deste modo, atenda-se a todos os direitos que a sociedade merece e possui.

Os princípios da livre iniciativa e da livre concorrência são de extrema importância para que haja o desenvolvimento econômico e social e, sem a presença deles não seria possível buscar a redução das desigualdades sociais e regionais, nem alcançar a "justiça social" apregoada pelo Art. 170 do texto constitucional. Deve existir um equilíbrio concorrencial, nos termos do art. 146-A da CF/88, que foi acrescentado pela Emenda Constitucional n. ${ }^{\circ}$ 42/2003.

Em linhas gerais, pode-se dizer que a liberdade de iniciativa econômica guarda relação com o livre exercício da atividade econômica, ao passo que a livre concorrência se baseia na isonomia, ou seja, em um ambiente em que as empresas estarão em situação equilibrada, num mesmo patamar, e onde não existem favorecimentos a umas em relação a outras, salvo quando a própria Constituição Federal especificar, a exemplo do artigo 170, 
inciso IX, que prevê a necessidade de proporcionar tratamento favorecido para as empresas de pequeno porte constituídas sob a égide das leis brasileiras, e que tenham sede e administração no Brasil (neste benefício também estão incluídas as microempresas).

A livre concorrência e a liberdade de iniciativa econômica são abordadas pontualmente por Fernando Facury Scaff (2006, pp. 110-111):

Uma primeira questão a ser enfrentada é a da distinção entre o conceito de liberdade de iniciativa econômica, constante do caput do art. 170 da Constituição, e o de livre-concorrência, inscrito no inciso IV daquele mesmo artigo.

Liberdade de iniciativa econômica decorre de um primado de liberdade, que permite a todo agente econômico, público ou privado, pessoa física ou jurídica, exercer livremente, nos termos das leis, atividade econômica em sentido amplo. Parte de um conceito de liberdade de exercício da profissão, para trabalhadores, e da liberdade do exercício de uma atividade econômica, para empresas.

Já a livre-concorrência funda-se primordialmente na isonomia, e não na liberdade (a qual, embora não esteja afastada, não é primordial). Busca-se criar as condições para que se realize um sistema de concorrência perfeita, dentro dos objetivos propostos pela Constituição da República em seu art. $3^{\circ}$, e respeitando os princípios da ordem econômica. Para que possa existir livreconcorrência é imperioso que haja isonomia entre os contendores na arena do mercado. A livre-concorrência repudia os monopólios, pois eles são sua antítese, sua negação. Cabe ao Estado criar condições para que haja livreconcorrência, não apenas com sua inação (exercício da liberdade), mas com ações concretas, reprimindo o abuso do poder econômico que vise à dominação dos mercados, à eliminação da concorrência e ao aumento arbitrário dos lucros. (itálico do autor).

Desta ponderação, é possível afirmar que a liberdade de iniciativa econômica se encontra intimamente relacionada com a liberdade, com o objetivo de permitir o exercício da atividade econômica de forma livre. Todavia, tal liberdade deve ser garantida em conjunto com a livre concorrência, fazendo com que a liberdade se relacione com a isonomia e, assim, não se formem cartéis ou monopólios. Com isso, o abuso do poder econômico será reprimido e o mercado não será dominado por uma ou poucas pessoas, o que traria um imenso prejuízo à sociedade (e também ao Estado, por consequência).

Por esses motivos, compete ao Estado regular e tutelar sempre que houver qualquer inconformidade ou desrespeito à $\mathrm{CF} / 88$, em especial nos casos em que houver abuso, formação de cartéis ou monopólio. Em casos como esses, “[...] o Estado deverá intervir na economia, a fim de impedir e não permitir mais o abuso na concorrência e manter, com isso, a harmonia da ordem econômica e social”. (CASTRO; GENOVEZ, 2014, p. 77). 
O Estado deve intervir na economia, e essa intervenção pode ocorrer por diversos modos, inclusive através de uma tributação mais ostensiva, caso haja lesão às normas constitucionais e que, notadamente, como é objeto do presente trabalho, lesem a livre concorrência. Ademais, outras são as formas de participação ativa do Estado, como na concessão de incentivos fiscais, a fim de organizar as empresas para que elas se estabeleçam em consonância com a livre iniciativa e a livre concorrência, e respeitem os princípios da ordem econômica.

A liberdade de iniciativa traz consigo duas vertentes, tanto jurídica, quanto econômica, e seu estudo deve ser vinculado às normas econômicas. Esse princípio deve garantir a justiça social (por esse motivo, também há uma ótima social envolvida, estritamente relacionada aos direitos fundamentais inerentes a todas as pessoas) bem como os demais princípios garantidores da ordem econômica (art. 170, CF/88) devem ser preservados.

Com isso, pode-se observar que esses dois princípios são importantes por garantirem que o mercado se mantenha em equilíbrio, bem como, por possibilitarem "[...] a redução das desigualdades regionais e sociais, e devem ser observados e fiscalizados pelo Estado, para que não haja excesso nas suas utilizações, salvaguardando, assim, os ditames da justiça social" (CASTRO; GENOVEZ, 2014, p. 79) e protegendo os direitos fundamentais.

A intervenção do Estado na economia deve ocorrer de forma ativa e efetiva caso os princípios da livre iniciativa e da livre concorrência (e também os demais princípios previstos no artigo 170 da CF/88) sejam descumpridos, com o objetivo de se reestabelecer o equilíbrio e a harmonia, garantindo o bem-estar social e a proteção estatal. Esse é um dever do Estado, de agir para proteger a sociedade e a economia, e garantir o equilíbrio nacional, o desenvolvimento econômico sustentável e o atendimento aos preceitos constitucionais e às necessidades sociais.

Para a atuação da livre concorrência na esfera jurídica, há de se levar em consideração três motivos fundamentais, tanto econômico, quanto político e social, conforme é abordado por Neide Teresinha Malard (2012):

Pode-se afirmar que a juridicização da livre concorrência decorre de três motivos fundamentais. Um motivo econômico, que se refere à promoção da eficiência econômica e do bem-estar social, a partir de uma adequada alocação de recursos, evitando-se distorções na distribuição do produto nacional, à medida que se garante o livre funcionamento dos mercados, sem necessidade de intervenção direta do Estado na economia. 
$[\ldots]$

A motivação sociológica estaria na legitimação da liberdade das decisões econômicas dos consumidores, empresários e trabalhadores.

$[\ldots]$

Por último, a motivação política estaria na necessidade de submeter-se a controle legal o poder econômico, em virtude da estreita correlação entre as forças econômicas e políticas, muitas vezes reunidas para a defesa de interesses privados que atentam contra a ordem política e até mesmo contra o regime democrático. A juridicização da concorrência teria, assim, a função preservadora da forma democrática de governo, assegurando a independência do Poder Público em relação ao poder econômico.

Esse seria o modelo ideal da concorrência, na forma descrita pela autora, e se isso ocorresse sem a intervenção do Estado, seria muito mais tranquilo e fácil de se fazer a administração estatal, pois o mercado funcionaria de forma eficiente, a população teria seu bem-estar social preservado, e a justiça social e os direitos fundamentais estariam garantidos, não havendo necessidade de intervenção estatal.

Todavia, não é isso que ocorre, pois, infelizmente, quando se trata de empresas, muitas das vezes elas têm por objetivo um lucro abusivo e, ante a ausência de concorrência (ou quando há um pequeno grupo que domina o mercado e relação a determinado produto), é necessária e indispensável a intervenção do Estado, para que o mercado restabeleça o equilíbrio.

Ademais, o Poder Público deve conceder tratamentos iguais aos contribuintes que se encontrarem em situação de igualdade, em respeito ao princípio da isonomia, denominado por Fernando Facury Scaff como princípio da neutralidade econômica. Para o autor:

Um dos requisitos para o exercício da livre-concorrência, que, como vimos, tem por base primordial o princípio da isonomia, é que os tributos sejam economicamente neutros para que não venham a distorcer os preços praticados pelas empresas dentro de um mesmo mercado relevante. Trata-se do princípio da neutralidade econômica dos tributos, que impede que este tipo de "intervenção econômica" do Estado cause desequilíbrios concorrenciais.

Entendo que o princípio da neutralidade econômica dos tributos pode ser encontrado em nosso sistema jurídico a partir do princípio da isonomia fiscal (art. 150, II, CF) que veda ao Poder Público o tratamento desigual entre contribuintes que se encontrem em situação equivalente, o que alcança, sem a menor sombra de dúvida, os aspectos concorrenciais. (SCAFF, 2006, p. 114). 
Faz parte, dentre os papeis do Estado, garantir que haja esse tratamento igualitário, e intervir no domínio econômico, caso constate que, por algum motivo, houve tratamento desigual a contribuintes que se encontravam em situação equivalente e que, portanto, mereciam igual tratamento.

Deste modo, a livre concorrência precisa respeitar as regras estabelecidas pelo Estado e pelo mercado, para que não cause lesões às demais empresas que defendem uma concorrência leal, pois isso poderia acarretar, inclusive, na falência e fechamento de várias empresas. A livre concorrência deve ter, como objetivo:

[...] um equilíbrio que deve se prestar, segundo a Constituição, de instrumento para o alcance de outros valores, destacando-se que deve assegurar a existência digna de todos, os valores sociais da justiça social com base no trabalho humano e na livre iniciativa. (RIBEIRO, 2012, p. 261-262).

Os princípios previstos no art. 170 da $\mathrm{CF} / 88$ devem ser respeitados pela livre iniciativa e pela livre concorrência, com o fim de se assegurar a dignidade da pessoa humana e os valores da justiça social e, caso alguma coisa saia do controle e haja um desequilíbrio que atente à ordem democrática, o Estado deverá (observe-se que não é uma faculdade) intervir na economia para que a ordem constitucional seja restabelecida.

O Estado tem o dever de propiciar condições iguais entre os concorrentes que se encontrem em situação equivalente pois, somente com isso, estará garantindo a proteção da livre concorrência e a prevenção para que não ocorram abusos (e, se esses ocorrerem, devem ser reprimidos, em conformidade com a $\mathrm{CF} / 88$ ).

Com isso, a livre iniciativa e a livre concorrência atuam como fundamentos da Ordem Econômica, não se deixando de lado os princípios previstos no art. 170 da CF/88. Embora esse dispositivo mencione expressamente apenas a livre concorrência, a livre iniciativa também é guiada pelos valores presentes no caput, para fins de garantia da justiça social e da proteção estatal.

A livre concorrência e a livre iniciativa possuem proteção constitucional, e também por meio de leis e demais institutos que objetivam garantir os princípios constitucionais (fundamentais, tributários e da ordem econômica), com a finalidade de se garantir a tão sonhada justiça social (e, por conseguinte, garantindo o bem-estar de toda a sociedade).

Todos os princípios mencionados (fundamentais, tributários e garantidores da ordem econômica) devem estar voltados para a proteção da sociedade e garantia ao cidadão e a todos 
os contribuintes os direitos previstos na Carta Constitucional, que é o principal instrumento normativo brasileiro.

Não obstante, “[...] a intervenção do Estado na economia dá-se de modo efetivo com a tributação, que propicia ao Estado fazer uma regulação econômica, desde que respeitando o texto constitucional" (CASTRO; GENOVEZ, 2014, p. 87). Por isso, pode-se observar que o Estado intervém na economia, mas tal intervenção possui limitação, vez que deve respeitar a todos os princípios constitucionais, com o objetivo de atender à justiça social e a todos os anseios da sociedade.

De mais a mais, cumpre salientar que:

Para que exista uma política extrafiscal efetiva, um real atendimento aos princípios garantidores da ordem econômica, e tributários, estabelecidos constitucionalmente, bem como para que as políticas públicas e sua implementação sejam efetivas, há necessidade de um equilíbrio concorrencial que não lese o Estado nem a sociedade, garantindo assim, o respeito à livre iniciativa e à livre concorrência. (CASTRO; GENOVEZ, 2014, p. 87).

$\mathrm{O}$ art. 146-A da CF/88 destaca que Lei Complementar, a ser estabelecida pelo Poder Legislativo, poderá estabelecer critérios especiais de tributação, para que se previnam desequilíbrios da concorrência. Ademais, sem prejuízo a isso, a União pode estabelecer normas com o mesmo objetivo, no intuito de se preservar o equilíbrio na concorrência. Esse dispositivo traz o que se denomina a intervenção por indução, que possibilita alternativas ao agente, podendo ser estimulados (recebendo incentivos) ou desestimulados (desincentivos) ao adotar determinada postura.

As normas tributárias não podem permitir (nem dar margem para) que haja desequilíbrio, devendo-se respeitar o texto constitucional e, quando houver qualquer lesão, surge a intervenção do Estado na economia, para coibir qualquer desequilíbrio que lese a sociedade (e, assim, a livre concorrência seja garantida de modo equilibrado, protegendo a isonomia e a dignidade humana).

Acerca dos critérios especiais destacados no disposto no artigo 146-A da CF/88, Maria de Fátima Ribeiro (2012, p. 268) disserta no seguinte sentido:

Já os critérios especiais destacados no artigo 146-A, destinam-se a viabilizar o correto recolhimento do tributo, quando o regime geral se mostre insuficiente. Assim, sendo instrumentos de realização de justiça tributária, os 
critérios especiais de tributação não podem ser utilizados com a finalidade de majorar a carga tributária. Tais critérios podem interferir com os elementos da obrigação principal ou estabelecer novas obrigações acessórias.

A nova competência estabelecida no artigo 146-A da Constituição Federal para a criação de critérios especiais de tributação deve atuar no sentido de impedir que a própria tributação seja um fator do desequilíbrio concorrencial.

Com o respeito a esses critérios é possível garantir efetivamente a justiça social prevista no art. 170 da $\mathrm{CF} / 88$ e tão sonhada pela sociedade, bem como a justiça tributária, necessária para que o mercado tenha uma organização equilibrada. Deste modo, serão asseguradas a livre concorrência e a isonomia (ou igualdade tributária), com a proteção aos contribuintes que estejam em situação equivalente, para que tenham um tratamento igual. A título de conclusão, Maria de Fátima Ribeiro (2012, p. 305-306) enfatiza que:

(6) É papel do Estado, verificar os limites da concorrência fiscal ao instituir seus tributos, bem como na forma de dispensar os contribuintes da incidência dos mesmos, evitando com isso, proporções negativas para a atividade econômica e na competitividade entre as empresas. O artigo 146-A da Constituição Federal brasileira ao dispor que, lei complementar poderá estabelecer critérios especiais de tributação, com o objetivo de prevenir desequilíbrios concorrenciais, embora forneça alguns caminhos, seguindo a tendência internacional (como por exemplo, o Código de Conduta da União Europeia), oferece algumas incertezas quanto ao seu alcance.

Após essa análise, é inegável a importância do equilíbrio concorrencial para a proteção social, pois garante a livre iniciativa e a livre concorrência e, por consequência, garante a efetividade e o respeito dos princípios constitucionais, não apenas os fundamentais, mas também os tributários e da ordem econômica, propiciando que as políticas públicas sejam efetivas e, com isso, a proteção dos direitos fundamentais de toda a população.

\section{Conclusão}

O Brasil tem passado por inúmeros problemas nos últimos anos, com crises nas esferas política, econômica e social, o que torna possível dizer que a democracia atual está em crise, e precisa de toda a coletividade para que não se rompam os aspectos democráticos da república. 
Por todo o cenário socioeconômico e político atual, a sociedade clama por um ambiente em que os direitos fundamentais sejam respeitados e efetivamente garantidos. Diversas são as formas de se garantir, ou proteger os indivíduos, para que a justiça social se concretize, pois a Constituição Federal é bem clara quanto ao regramento dos direitos e garantias fundamentais e à necessidade de sua proteção.

Uma das formas para que essa proteção se dê é através da esfera tributária, mais notadamente por meio da função social do tributo e das políticas fiscais e extrafiscais, que permitem a busca pela redução das desigualdades sociais e regionais, propiciando um desenvolvimento econômico e social (não apenas crescimento, mas também com o cuidado ao meio ambiente e, além disso, com a preocupação dos aspectos sociais). Para tanto, políticas públicas são adotadas nesse sentido, como é o caso da Zona Franca de Manaus mencionada no presente trabalho.

Em consonância a esses mecanismos, há a livre iniciativa e a livre concorrência que, em uma primeira vista, tende a garantir a liberdade do mercado e das empresas para concorrerem entre si, mas sua visão vai além, pois tem um nítido caráter social envolvido, pois o Estado pode intervir na economia nos casos em que empresas querem lesar a sociedade, garantindo monopólios ou formando cartéis, e prejudicando o equilíbrio social.

Desta feita, a livre iniciativa e a livre concorrência são importantes, pois darão alternativas à sociedade, em razão da competição, para uma melhoria da qualidade de vida de todos, efetivando, assim, os direitos fundamentais sempre buscados pelas pessoas. As empresas têm a obrigação de respeitar o texto constitucional e a sociedade e, quando assim não o for, o Estado tem o dever de intervir na economia, a fim de evitar arbitrariedades dessas empresas e garantir o bem-estar social.

Somente com essa proteção é que será possível garantir a efetividade da Constituição Cidadã, que já completou 30 anos em 2018 e deve permanecer a cada dia mais forte e presente na sociedade, garantindo a justiça social (e os princípios da ordem econômica que se aliam a ela, no artigo 170 do texto constitucional, bem como os princípios fundamentais e tributários) e a soberania nacional, para que a dignidade da pessoa humana e os direitos fundamentais sejam devidamente protegidos e respeitados.

\section{Bibliografia.}


AMARO, Luciano. Direito Tributário Brasileiro. 15. ed. São Paulo: Saraiva, 2009

ÁVILA, Humberto. Sistema Constitucional Tributário. 4. ed. São Paulo: Saraiva, 2010.

BRASIL. Constituição da República Federativa do Brasil de 1988. Disponível em <<http://www.planalto.gov.br/ccivil_03/constituicao/constituicao.htm〉>. Acesso em 17 fev. 2020.

CANOTILHO, José Joaquim Gomes. Direito Constitucional e Teoria da Constituição. 7. ed. Revista, atualizada e ampliada. Coimbra: Almedina, 2006.

CARRAZZA, Roque Antônio. Curso de Direito Constitucional Tributário. 27. ed. São Paulo: Malheiros, 2011.

CASTRO, Aldo Aranha de; GENOVEZ, Simone. A aplicabilidade dos princípios da livre iniciativa e da livre concorrência com vistas ao desenvolvimento econômico. In: Hertha Urquiza Baracho; Gina Vidal Marcílio Pompeu; Everton das Neves Gonçalves. (Org.). Direito e Economia I. 1ed.Florianópolis: CONPEDI, 2014, v. 1, p. 74-92.

COÊLHO, Sacha Calmon Navarro. Curso de Direito Tributário Brasileiro. 11. ed. Rio de Janeiro: Forense, 2010.

ELALI, André. Incentivos Fiscais, Neutralidade da Tributação e Desenvolvimento Econômico: a Questão da Redução das Desigualdades Regionais e Sociais. in INCENTIVOS FISCAIS - questões pontuais nas esferas federal, estadual e municipal. coord. André Elali, Ives Gandra da Silva Martins e Marcelo Magalhães Peixoto. São Paulo: MP, 2007.

GRAU, Eros Roberto. A Ordem Econômica na Constituição de 1988. 14. ed. São Paulo: Malheiros, 2010.

MALARD, Neide Teresinha. A liberdade de iniciativa e a livre concorrência: as questões jurídicas do poder econômico. Disponível em:

$<<$ http://www.iesb.br/ModuloOnline/Atena/arquivos_upload/Neide\%20Teresinha\%20Malard .pdf>>. Acesso em: 17/11/2012.

MEYER-PFLUG, Samantha. Do Princípio da Legalidade e da Tipicidade. in: Curso de Direito Tributário. 13. ed. coord. Ives Gandra da Silva Martins. São Paulo: Saraiva, 2011. 
MORO, Maitê Cecília Fabbri. Dicionário Brasileiro de Direito Constitucional. Coordenador Geral Dimitri Dimoulis. São Paulo: Saraiva, 2007.

NABAIS, José Casalta. O dever fundamental de pagar impostos. Coimbra: Almedina, 1998.

RIBEIRO, Maria de Fátima; CASTRO, Aldo Aranha de. A Função Social do Tributo e a Implementação de Políticas Públicas. Disponível em $<<$ http://www.publicadireito.com.br/artigos/?cod=5f8a7deb15235a12 > . 2013. Acesso em 22 jul. 2019.

RIBEIRO, Maria de Fátima. A incidência tributária ambiental no desenvolvimento econômico sustentável e a função social do tributo. In: DIREITO TRIBUTÁRIO E SEGURANÇA JURÍDICA. coord. Maria de Fátima Ribeiro. São Paulo: MP, 2008.

RIBEIRO, Maria de Fátima. Reflexos da Tributação no Desequilíbrio da Livre Concorrência. In: CAVALCANTE, Denise Lucena; GRUPENMACHER, Betina Treiger; QUEIROZ, Mary Elbe; RIBEIRO, Maria de Fátima. Novos Horizontes da Tributação: um Diálogo LusoBrasileiro. Coimbra: Almedina, 2012.

SARLET, Ingo Wolfgang. O Princípio da Dignidade da Pessoa Humana e os Direitos Fundamentais. 2. ed. Porto Alegre: Livraria do Advogado, 2002.

SCAFF, Fernando Facury. Efeitos da Coisa Julgada em Matéria Tributária e Livreconcorrência. In: Coisa Julgada, Constitucionalidade e Legalidade em Matéria Tributária. coord. Hugo de Brito Machado. São Paulo: Dialética; e Fortaleza: ICET, 2006. 